\title{
Prediction of Flexural Capacity of RC Beams Strengthened in Flexure with FRP Fabric and Cementitious Matrix
}

\author{
Kyusan Jung, Kinam Hong, Sanghoon Han, Jaekyu Park, and Jaehyun Kim \\ Department of Civil Engineering, Chungbuk National University, 1 Chungdae-ro, Seowon-gu, Cheongju, \\ Chungbuk 362-763, Republic of Korea \\ Correspondence should be addressed to Kinam Hong; hong@cbnu.ac.kr
}

Received 1 August 2015; Revised 28 September 2015; Accepted 28 September 2015

Academic Editor: Osman Gencel

Copyright (C) 2015 Kyusan Jung et al. This is an open access article distributed under the Creative Commons Attribution License, which permits unrestricted use, distribution, and reproduction in any medium, provided the original work is properly cited.

\begin{abstract}
This paper presents both experimental and analytical research results for predicting the flexural capacity of reinforced concrete (RC) beams strengthened in flexure with fabric reinforced cementitious matrix (FRCM). In order to assess the efficiency of the FRCM-strengthening method, six beams were strengthened in flexure with FRCM composite having different amounts and layers of FRP fabric and were tested under four-point loading. From test results, it was confirmed that the slippage between the FRP fabric and matrix occurs at a high strain level, and all of the FRCM-strengthened beams failed by the debonding of the FRCM. Additionally, a new bond strength model for FRCM considering the slippage between fabric and matrix was proposed, using a test database to predict the strengthening performance of the FRCM composite. The prediction of the proposed bond strength model agreed well with the debonding loads of the test database.
\end{abstract}

\section{Introduction}

Fabric reinforced cementitious matrix (FRCM) composites were developed to strengthen deteriorated reinforced concrete structures and have been employed during the last two decades [1]. Unlike externally bonded fiber reinforced polymer (FRP) systems, epoxy resin is not used for the FRCM-strengthening method. The FRP fabric used in the FRCM-strengthening method is attached by using a cementitious matrix, an inorganic material, instead of epoxy resin [2]. The use of an inorganic material can solve various problems that result from the use of epoxy resin [3]. The major problems associated with epoxy resin are its low glass transition temperature, difficulty of application at low temperatures, inability to apply to humid surfaces, and lack of vapor permeability [1]. Additionally, FRCM composite has higher fire resistance than externally bonded FRP sheets and laminates [4]. However, the mechanical properties of a cementitious matrix, such as bond strength, are generally lower than those of epoxy resin. Thus, the FRP materials in the FRCM-strengthening method are shaped like fabric or textile to improve the bond strength of the FRP reinforcement [5].
Many experimental studies have been performed to verify the efficiency of the FRCM-strengthening method. D'Ambrisi and Focacci [3] investigated the flexural performance of RC beams strengthened with FRCM composite using two different FRP net materials, carbon fiber net and polyparaphenylene benzobisoxazole (PBO) fiber net, and shapes. It was confirmed from their study that PBO-FRCM performs better than carbon-FRCM and the variation of the debonding strain with the number of layers is more gradual than that of FRP materials [3]. Additionally, they insisted that it is necessary to identify more representative material parameters which can describe the mechanical behavior of different types of matrices in relation to the adapted type of fibers [3]. Ombres [6] investigated the flexural performance of RC beams strengthened with PBO-FRCM composite and predicted their flexural behavior by using various existing bond strength models for externally bonded reinforced FRP. Based on his research results, he suggested that when debonding failures occur, the predictions of the existing bond strength model are not accurate and a more accurate and reliable debonding model for FRCM-strengthened RC beams should be developed [6]. Loreto et al. [7] evaluated the performance of RC slab strengthened with PBO-FRCM composite by 


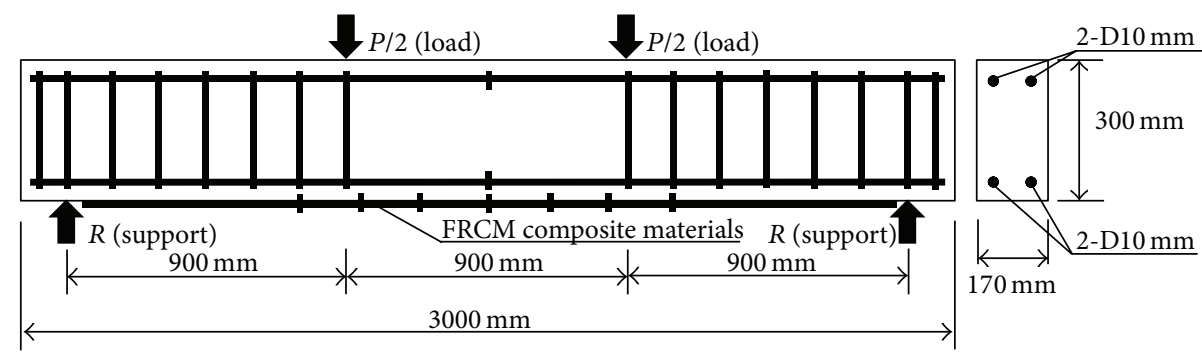

I Strain gages

Figure 1: Test specimen layout.

three-point bending test and performed an analytical study to verify the level of accuracy of the ultimate capacity prediction according to the ACI 549 [8] guide, where the proposed equations are based on the conventional reinforced concrete theory. Through the results of their study, they reported that the ultimate capacity prediction according to the ACI 549 [8] guide was satisfactory because the tensile properties used in the analysis did not depend on fiber rupture but are based on the performance of the FRCM tensile coupon during the crack formation zone [7]. Babaeidarabad et al. [1] tested FRCM-strengthened beams having 1-ply and 4ply PBO fabric and predicted the efficiency of the FRCMstrengthening method through a section analysis, following methodology in accordance with ACI 549 [8] and ACI 318 [9]. Their research results showed that the strain compatibility of a beam with 1-ply fabric was no longer satisfied, due to fabric slippage within the matrix after steel yielding. They noted that the slippage behavior can be captured in the analysis by the tensile characteristic parameters obtained from FRCM coupon testing [1].

Meanwhile, several studies to identify the bond-slip behavior between the fiber/matrix and FRCM/concrete interface have been performed by a few researchers. Ombres [4] carried out an experimental and theoretical study on the bond-slip behavior between concrete and PBO-FRCM composite and proposed a nonlinear bond-slip model for FRCM using the experimental data. However, the parameters of his model should be calibrated using more experimental data. D'Ambrisi et al. [10] experimentally and analytically evaluated the bond stress between CFRP-FRCM materials and masonry and reported that the debonding occurs at the fibers/matrix interface after a considerable fibers/matrix slip. Also, D'Ambrisi et al. [11] performed an experimental study on the bond-slip between PBO-FRCM and concrete and reported that the debonding strain in $\mathrm{PBO}$ fibers decreased in proportion to $1 / \sqrt{n}$ with an increase in the number of layers, $n$.

Although some studies on the bond-slip behavior of fiber/matrix and FRCM/concrete interface have been performed, a bond strength model for FRCM has not been established yet. Moreover, the ACI 549 [8] guideline applicable for predicting the strengthening efficiency of FRCM composite also requires an additional FRCM coupon test, to define the tensile characteristic parameters of the FRCM composite. Thus, this study aimed to perform the flexural tests including
TABLE 1: Mixture properties of concrete.

\begin{tabular}{lcccccc}
\hline \multirow{2}{*}{ W/C (\%) } & \multirow{2}{*}{ S/a (\%) } & \multicolumn{5}{c}{ Unit weight $\left(\mathrm{kg} / \mathrm{m}^{3}\right)$} \\
& & $\mathrm{W}$ & $\mathrm{C}$ & $\mathrm{S}$ & $\mathrm{G}$ & $\mathrm{Ad}^{(\mathrm{a})}$ \\
\hline 48.4 & 48.1 & 168 & 345 & 860 & 949 & 2.07 \\
\hline
\end{tabular}

${ }^{(\mathrm{a})} \mathrm{AE}$ water-reducing admixture.

TABLE 2: Mechanical properties of rebar used.

\begin{tabular}{lcccc}
\hline $\begin{array}{l}\text { Nominal } \\
\text { diameter } \\
(\mathrm{mm})\end{array}$ & $\begin{array}{c}\text { Modulus of } \\
\text { elasticity } \\
(\mathrm{MPa})\end{array}$ & $\begin{array}{c}\text { Yield } \\
\text { strength } \\
(\mathrm{MPa})\end{array}$ & $\begin{array}{c}\text { Ultimate } \\
\text { strength } \\
(\mathrm{MPa})\end{array}$ & $\begin{array}{c}\text { Elongation } \\
(\%)\end{array}$ \\
\hline 9.53 & $2.0 \times 10^{5}$ & 480 & 590 & 17.1 \\
\hline
\end{tabular}

the number of plies and the amount of FRP fabric as test variables and to develop a bond strength model to predict the flexural behavior of FRCM-strengthened beams without an additional test.

\section{Experimental Program}

2.1. Test Specimens. The experimental program consisted of seven beams of $3,000 \mathrm{~mm}$ and a cross section of $170 \times$ $300 \mathrm{~mm}$. Two deformed bars were placed on the tension and compression faces, respectively. Shear reinforcements were placed in a center-to-center spacing of $150 \mathrm{~mm}$ to prevent shear failure in all specimens. Steel reinforcement of D10 with a nominal diameter of $9.53 \mathrm{~mm}$ was used for tension, compression, and shear reinforcement. The side and vertical concrete cover was kept at $30 \mathrm{~mm}$ for all beams. The details of the test specimens are presented in Figure 1.

2.2. Materials. Ready-mix concrete was used to fabricate the beams. The mixture properties of the concrete used are tabulated in Table 1.

Six standard concrete cylinders with dimensions of $\Phi 100 \mathrm{~mm} \times 200 \mathrm{~mm}$ were cast and tested according to ASTM C39/C39M [12]. The average compressive strength of the concrete obtained from the compressive tests for the cylinders was $28.0 \mathrm{MPa}$ at the age of 28 days. Mechanical properties of rebar were determined by the direct tensile tests for three coupons in accordance with ASTM A370 [13] in the laboratory. Material properties of the rebar used were taken from tests and are given in Table 2. 


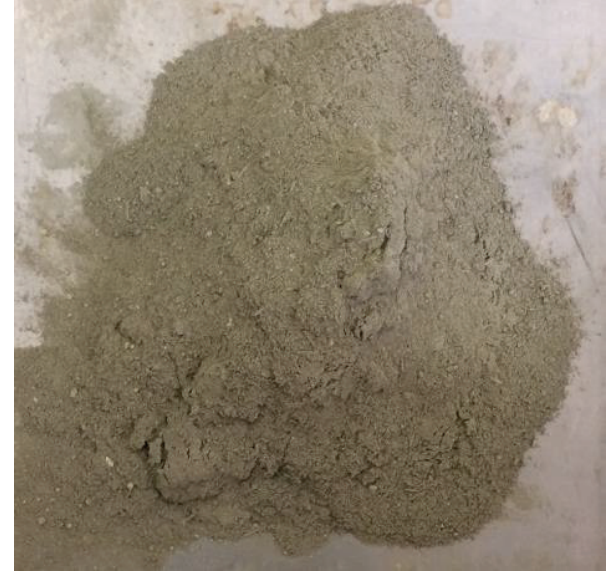

(a) Cementitious matrix

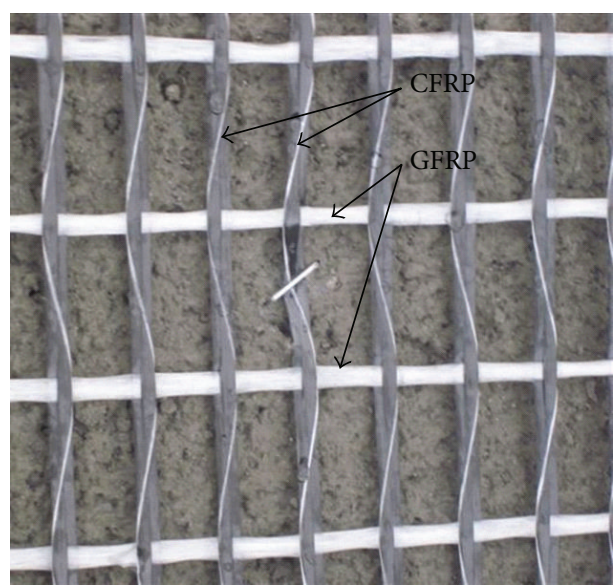

(b) FRP fabric

FIGURE 2: Components of FRCM composite.

TABLE 3: Mechanical properties of cementitious matrix.

\begin{tabular}{lcc}
\hline & $\begin{array}{c}\text { Elastic modulus } \\
(\mathrm{GPa})\end{array}$ & $\begin{array}{c}\text { Compression strength } \\
(\mathrm{MPa})\end{array}$ \\
\hline $\begin{array}{l}\text { Cementitious } \\
\text { matrix }\end{array}$ & 40 & 45 \\
\hline
\end{tabular}

The cementitious matrix and FRP fabric used for flexural strengthening of RC specimens are shown in Figures 2(a) and 2(b), respectively. The cementitious matrix consisted of microcement, fine aggregate, polypropylene staple fiber, and admixtures. The compressive strength of the cementitious matrix was determined from a compression test of five cubes of $50 \mathrm{~mm}$ size according to ASTM C109/C109M [14] and measured as $45 \mathrm{MPa}$ at the age of 28 days. Table 3 presents the mechanical properties of the cementitious matrix obtained from the compression test.

As shown in Figure 2(b), the FRP fabric consisted of CFRP and GFRP strips. Black CFRP and white GFRP strips were laid in the warp direction and weft direction, respectively, at spacings of $17 \mathrm{~mm}$ and $33 \mathrm{~mm}$. The FRP fabric was divided into Type A and Type B by the amount of CFRP fiber per strip. The cross-sectional areas of a CFRP strip for Types $\mathrm{A}$ and $\mathrm{B}$ were 1.8 and $2.7 \mathrm{~mm}^{2}$, respectively. Additionally, the nominal thicknesses of FRP fabric for Types A and B were $0.0107 \mathrm{~mm}$ and $0.0162 \mathrm{~mm}$, respectively. The mechanical properties of the FRP fabric offered by manufacturers are presented in Table 4.

2.3. Test Program. The test variables included the number of plies and the amount of FRP fabric. An unstrengthened specimen used to relatively assess the strengthening performance of FRCM was labeled as Control. Specimens strengthened with FRP fabric were labeled using a one-letter abbreviation and an Arabic number. The first letter, A or B, represents Type A or B of the FRP fabric, respectively. The following Arabic number, 1, 2, or 3, represents the application of 1-ply,
TABLE 4: Mechanical properties of FRP fabric.

\begin{tabular}{lcccc}
\hline Type & $\begin{array}{c}\text { Nominal } \\
\text { thickness } \\
(\mathrm{mm})\end{array}$ & $\begin{array}{c}\text { Elastic } \\
\text { modulus } \\
(\mathrm{GPa})\end{array}$ & $\begin{array}{c}\text { Ultimate } \\
\text { tensile strength } \\
(\mathrm{MPa})\end{array}$ & $\begin{array}{c}\text { Ultimate } \\
\text { tensile strain } \\
(\%)\end{array}$ \\
\hline $\mathrm{A}$ & 0.107 & 240 & 4,300 & 1.75 \\
$\mathrm{~B}$ & 0.162 & 240 & 4,300 & 1.75 \\
\hline
\end{tabular}

TABLE 5: Test variables.

\begin{tabular}{lccc}
\hline Group & Specimen ID & Type of FRP fabric & Number of plies \\
\hline & Control & - & - \\
\hline \multirow{2}{*}{ A } & A1 & & 1 \\
& A2 & Type A & 2 \\
& A3 & & 3 \\
\hline \multirow{3}{*}{ B } & B1 & & 1 \\
& B2 & Type B & 2 \\
& B3 & & 3 \\
\hline
\end{tabular}

2-ply, or 3-ply FRP fabric on the bottom face of the specimen, respectively. Table 5 illustrates the test variables.

2.4. Strengthening Procedure. The strengthening procedure of the FRCM composite was as follows. (1) The first layer of cementitious matrix with a nominal thickness of $2 \mathrm{~mm}$ was applied on the bottom surface of the specimen. (2) The precut FRP fabric was laid on the cementitious matrix. (3) The second layer of cementitious matrix with a nominal thickness of $2 \mathrm{~mm}$ was applied on the FRP fabric. In the case of strengthening with 2-ply and 3-ply FRP fabric, the above procedure was repeated two and three times, respectively. The nominal thickness of FRCM with 1-ply FRP fabric was taken as approximately $5 \mathrm{~mm}$. The bond length of FRP fabric was $2,600 \mathrm{~mm}$ regardless of the number of FRP fabric layers. Flexural tests were performed after 28 days of strengthening to allow the cementitious matrix to develop sufficient strength. 
TABLE 6: Summary of experimental results.

\begin{tabular}{|c|c|c|c|c|}
\hline Specimen ID & Ultimate load $(\mathrm{kN})$ & $\begin{array}{c}\text { Deflection at ultimate } \\
\text { load }(\mathrm{mm})\end{array}$ & $\begin{array}{l}\text { Percent increase } \\
\text { over Control (\%) }\end{array}$ & Failure mode \\
\hline Control & 44.5 & 11.0 & - & Flexure \\
\hline $\mathrm{A} 1$ & 58.6 & 18.0 & 131.7 & Debonding \\
\hline A2 & 62.7 & 15.5 & 141.0 & Debonding \\
\hline $\mathrm{A} 3$ & 83.6 & 22.0 & 187.9 & Debonding \\
\hline $\mathrm{B} 1$ & 65.5 & 22.9 & 147.2 & Debonding \\
\hline B2 & 73.7 & 15.6 & 165.6 & Debonding \\
\hline B3 & 97.8 & 21.6 & 219.8 & Debonding \\
\hline
\end{tabular}

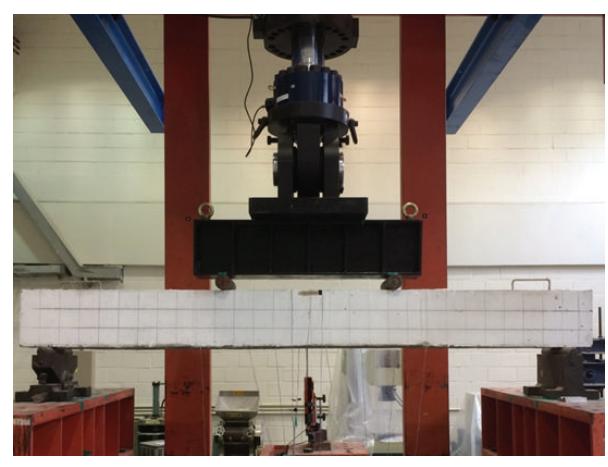

Figure 3: Test setup.

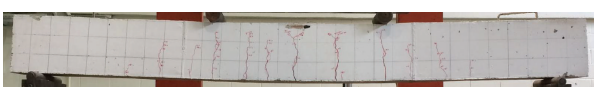

(a) Control

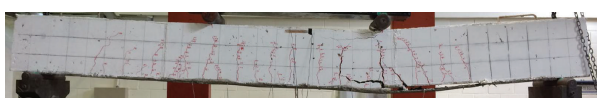

(b) A3

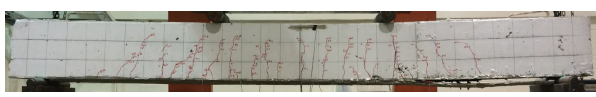

(c) B3

Figure 4: Failure modes of specimens.
2.5. Test Setup. All beams were tested using a simply supported system with a net span of $2,700 \mathrm{~mm}$. The tests for all beams were performed under four-point loading, as shown in Figure 3.

Load was applied at a stroke rate of $0.4 \mathrm{~mm} / \mathrm{min}$ by a hydraulic actuator with a maximum capacity of $2,000 \mathrm{kN}$. The load was measured by a load cell. The deflections were measured by Linear Variable Differential Transducers (LVDTs) at midspan. As shown in Figure 1, the strains of FRP fabric were measured by seven strain gauges attached on CFRP strip at the spacing of $200 \mathrm{~mm}$. The strains in the concrete and steel rebars at the midspan of each beam were measured by strain gauges. The strain in the concrete was measured by a strain gauge placed on the top of each beam before testing. For steel rebar, strain was measured by a strain gauge mounted in each tension rebar before concrete casting. The load and strains were recorded by using a data logger. During the test, the propagation of crack and damage of FRCM composite were visually inspected and recorded on the surface of the beam.

\section{Test Results and Discussion}

3.1. Summary of Test Results. The test results for ultimate load, deflection, and failure mode of each specimen are presented in Table 6 . The flexural strengths of beams strengthened with FRCM composite increased from $131.7 \%$ to $219.8 \%$ relative to the Control specimen. The ultimate load of the FRCMstrengthened beams increased with a higher amount of FRP fabric, and all of them failed by the debonding of the FRCM composite.

3.2. Failure Mode. Figure 4 shows the failure modes of representative specimens in each group. The initial crack of the Control specimen occurred at the midspan under a load of $21.8 \mathrm{kN}$. New vertical cracks occurred with the increase in applied load and the initial cracks were progressed toward the compressive zone. With the increase of applied load, the vertical cracks extended about $90 \%$ of the height of the cross section. Finally, the Control specimen failed due to the yielding of tensile reinforcement followed by crushing of the concrete compressive zone (see Figure 4(a)).

In the case of specimen A3 strengthened with 3-ply FRP fabric, an initial crack occurred at the load of $25.9 \mathrm{kN}$ and then the crack pattern produced by the increase of applied load was similar to that of the Control. The average spacing of vertical flexural cracks was approximately $100 \mathrm{~mm}$ and much closer than that of Control. The interfacial debonding of the FRCM composite started at the vertical crack under a loading point and gradually progressed toward a right support (see Figure 4(b)). However, failure began with the concrete cover ripping-off before complete debonding of the FRCM composite happened. Eventually, it failed by FRCM composite debonding followed by the crushing of the concrete compressive zone between two loading points.

The initial crack load of specimen B3 with the FRP fabric of Type B occurred at the load of $30.9 \mathrm{kN}$. Until the applied load attained approximately $95 \mathrm{kN}$, no debonding of 


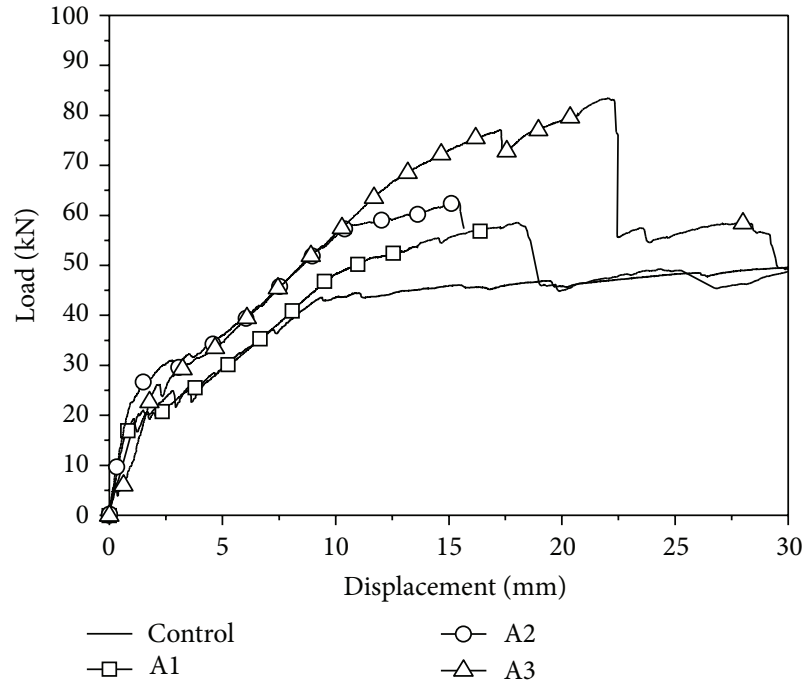

(a) Group A

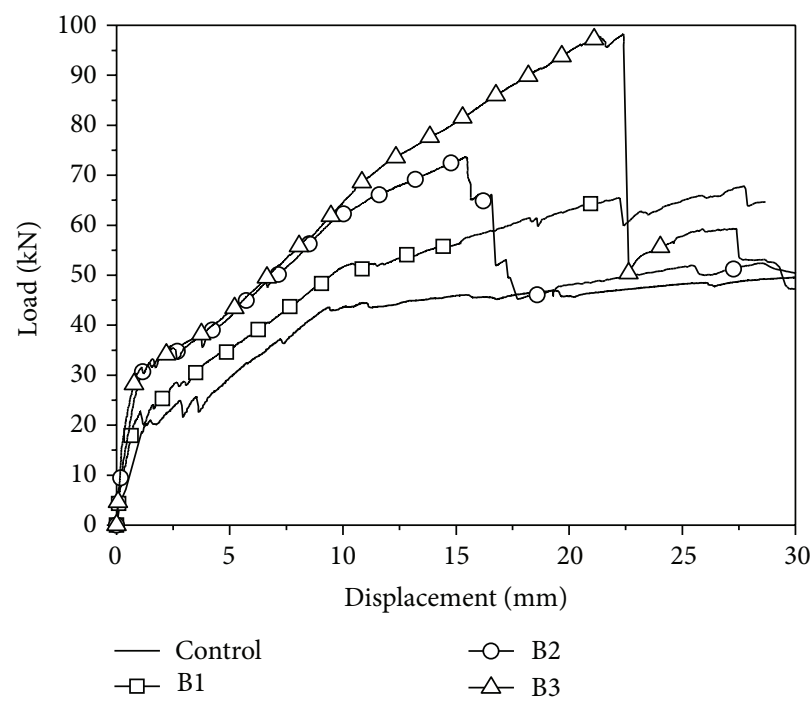

(b) Group B

FIGURE 5: Load-displacement curves of specimens.

the FRCM composite was observed in the specimen. However, once the load reached the maximum load of $97.8 \mathrm{kN}$, the debonding of FRCM composite suddenly occurred at the right side of the specimen (see Figure $4(\mathrm{c})$ ). The crack pattern of specimen B3 was similar to that of specimen A3, but the debonding process of the FRCM composite was different.

3.3. Comparison of Load-Deflection Curves. Figures 5(a) and 5(b) show the load-deflection curves of specimens in Groups $A$ and $B$, respectively.

The initial flexural stiffness of specimens in Groups A and $\mathrm{B}$ was higher than that of the Control specimen but was not proportional to the amount of FRP fabric. This is due to the fact that the strengthening effect of an externally bonded reinforced system is exhibited after the occurrence of an initial crack. Flexural stiffness after the yielding of tensile steel represents the effect of the amount of FRP fabric, as shown in Figures 5(a) and 5(b). Additionally, the maximum load of the specimens significantly increased with a greater number of FRP fabric layers. The maximum loads of specimens A1, $\mathrm{A} 2$, and $\mathrm{A} 3$ in Group A were $58.6 \mathrm{kN}, 62.7 \mathrm{kN}$, and $83.6 \mathrm{kN}$, respectively. The maximum loads of specimens $\mathrm{B} 1, \mathrm{~B} 2$, and $\mathrm{B} 3$ were $65.5 \mathrm{kN}, 73.7 \mathrm{kN}$, and $97.8 \mathrm{kN}$, respectively. However, the maximum loads were not proportional to the number of FRP fabric layers in both Group A and Group B. On the other hand, the strengthening performances of $\mathrm{B} 1, \mathrm{~B} 2$, and $\mathrm{B} 3$ with Type B of FRP fabric were higher than those of A1, A2, and A3 with Type A, respectively. This resulted from the difference in the amount of FRP fiber. As mentioned before, the nominal thicknesses of the FRP fabric layer for Types A and B were $0.0107 \mathrm{~mm}$ and $0.0162 \mathrm{~mm}$, respectively. Therefore, it can be concluded that Type B is more effective than Type A for the FRCM-strengthening method.
3.4. Relationship of Load-FRP Fabric Strain. Figures 6(a) and 6(b) show comparisons of load-FRP fabric strain curves measured at the midspan of specimens in Groups A and B. The load-strain curves of all specimens in Groups $A$ and $B$ exhibited a trend in which the tensile strain of the FRP fabric rapidly increased after the occurrence of an initial crack. In particular, the FRP fabric strain of specimen A1 increased much rapidly compared to those of other specimens. It is because the contribution of cementitious matrix to the tensile strength is transferred to FRP fabric after the formation of initial crack at midspan, so that the FRP fabric of specimen Al with the lowest fabric amount contributes much higher tensile strength than other specimens. The strains of specimens in Groups A and B ultimately reached approximately $8,000 \mu \varepsilon$ and $12,000 \mu \varepsilon$, respectively. Although the maximum strains of specimens in Group B were higher than those of specimens in Group A, these were less than 70\% of the strain corresponding to FRP fabric rupture, 17,500 $\mu \varepsilon$. Before initial crack occurrence, the relationship of loadFRCM fabric strain was linear. However, the relationship after initial crack became nonlinear, resulting from the bondslip behavior between the FRCM fabric and cementitious matrix.

3.5. Strain Distribution at a Midspan Cross Section. Figures 7 (a) and 7(b) show the strain distribution along the depth at a midspan cross section of representative specimens of Groups A and B. The strains of concrete, tensile rebar, and FRP fabric were checked at representative load stages. It can be observed from Figure 7 that the neutral axis rises and the slippage between FRP fabric and the cementitious matrix increases with the higher load. Consequently, it should be noted that the strain distribution of a section at low strain can be assumed to be linear, but it cannot be regarded as linear at 

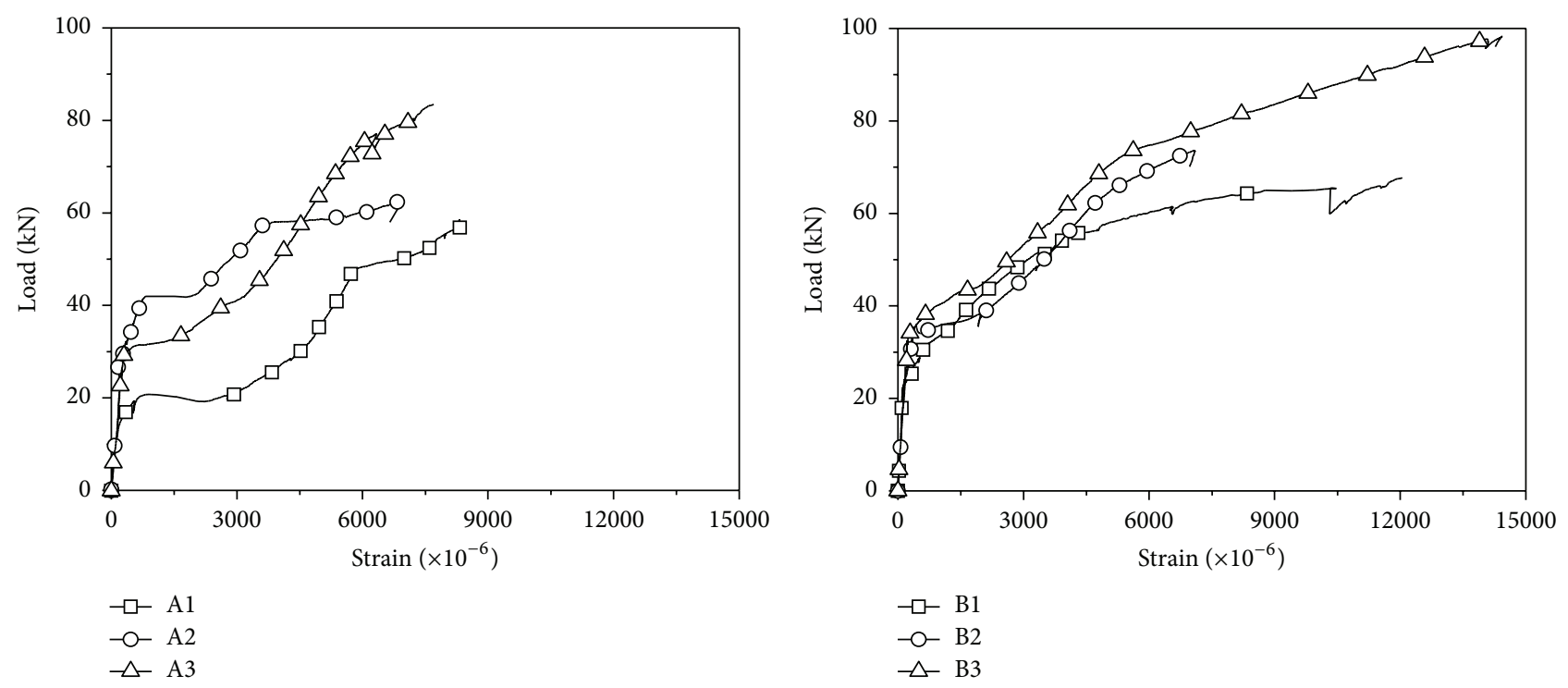

(a) Group A

(b) Group B

FIGURE 6: Comparisons of load-FRP fabric strain curves.

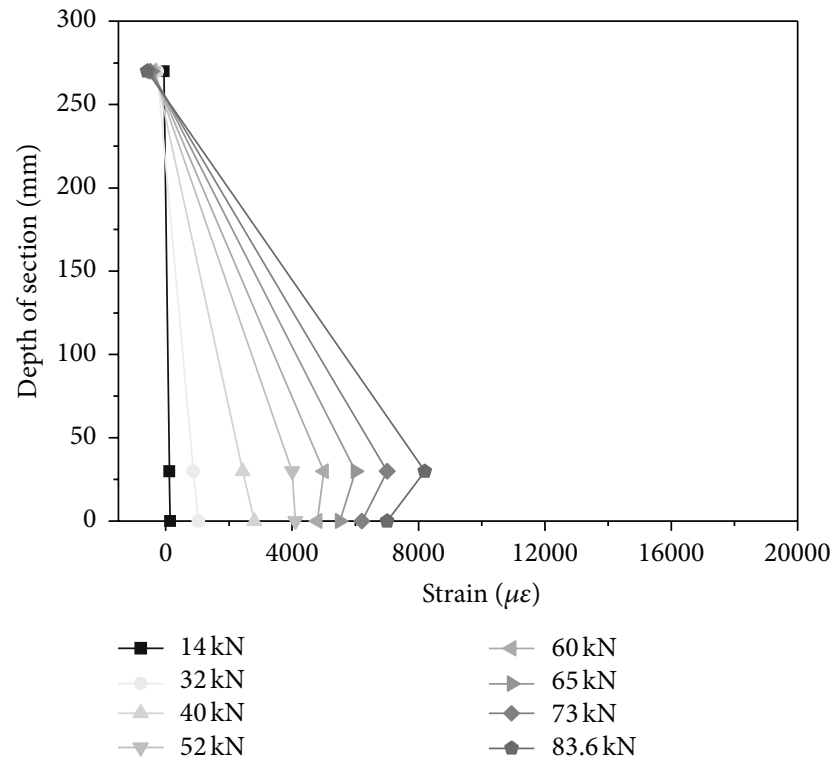

(a) A3

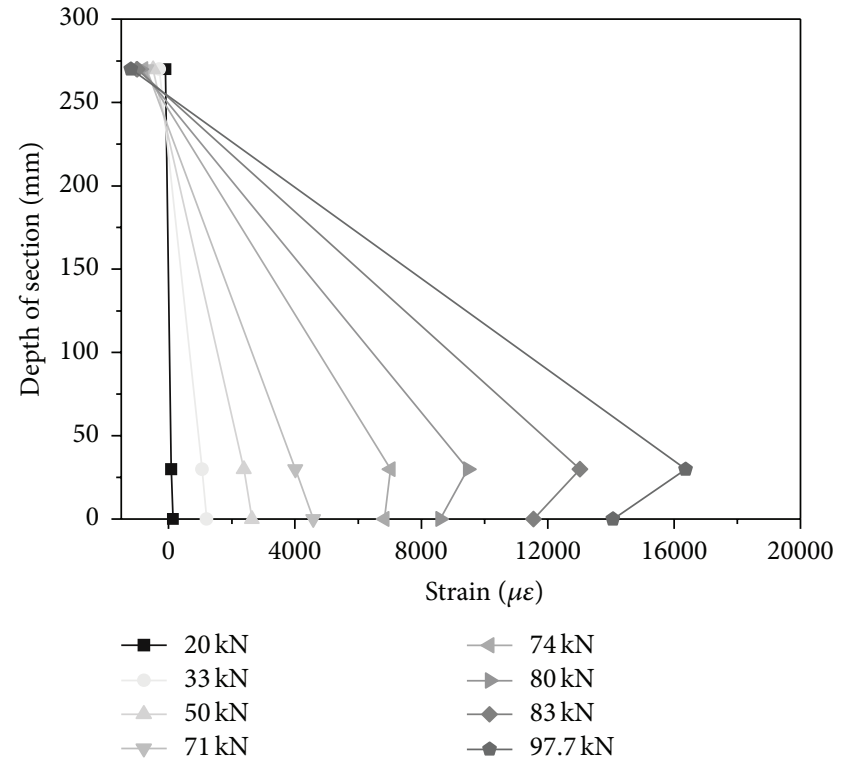

(b) $\mathrm{B} 3$

FIGURE 7: Strain distributions at a midspan section.

the high strain level, due to the slippage between FRP fabric and cementitious matrix.

\section{Numerical Analysis}

4.1. Proposition of Bond Strength Model. The bond strength model proposed by Teng et al. [15] has been well known as a model for externally bonded reinforcement (EBR). Although the bond-slip behavior of the FRCM composite is different from that of EBR due to the adhesive being used, it was considered that the bond-slip concept based on fracture mechanics was similar in both cases. Therefore, a new bond strength model, which was based on the model by Teng et al. [15], was used to evaluate the effective stress of the FRCM composite in this study. Equation (1) shows the model by Teng et al. [15]:

$$
\sigma_{p}=\alpha \beta_{p} \beta_{L} \sqrt{\frac{E_{p} \sqrt{f_{c}^{\prime}}}{t_{p}}},
$$


TABLE 7: Database for RC beams strengthened with FRCM composite.

\begin{tabular}{|c|c|c|c|c|c|c|c|c|c|c|}
\hline Reference & Specimen ID & $b_{c}(\mathrm{~mm})$ & $d(\mathrm{~mm})$ & $h(\mathrm{~mm})$ & $A_{s}\left(\mathrm{~mm}^{2}\right)$ & $f_{y}(\mathrm{MPa})$ & $f_{c}^{\prime}(\mathrm{MPa})$ & $E_{f}(\mathrm{GPa})$ & $t_{1}(\mathrm{~mm})$ & Number of plies \\
\hline \multirow{6}{*}{ Project study } & $\mathrm{A} 1$ & 170 & 270 & 300 & 142.6 & 480 & 28.0 & 240 & 0.107 & 1 \\
\hline & A2 & 170 & 270 & 300 & 142.6 & 480 & 28.0 & 240 & 0.107 & 2 \\
\hline & A3 & 170 & 270 & 300 & 142.6 & 480 & 28.0 & 240 & 0.107 & 3 \\
\hline & B1 & 170 & 270 & 300 & 142.6 & 480 & 28.0 & 240 & 0.162 & 1 \\
\hline & B2 & 170 & 270 & 300 & 142.6 & 480 & 28.0 & 240 & 0.162 & 2 \\
\hline & B3 & 170 & 270 & 300 & 142.6 & 480 & 28.0 & 240 & 0.162 & 3 \\
\hline \multirow{4}{*}{ Babaeidarabad et al. [1] } & L_1 & 152 & 260 & 305 & 258 & 276 & 29.1 & 280 & 0.05 & 1 \\
\hline & L_4 & 152 & 260 & 305 & 258 & 276 & 29.1 & 280 & 0.05 & 4 \\
\hline & H_1 & 152 & 260 & 305 & 258 & 276 & 42.91 & 280 & 0.05 & 1 \\
\hline & $\mathrm{H}_{-} 4$ & 152 & 260 & 305 & 258 & 276 & 42.91 & 280 & 0.05 & 4 \\
\hline \multirow{4}{*}{ Ombres [6] } & S2_T1_P2 & 150 & 230 & 250 & 157 & 525.9 & 23.02 & 270 & 0.045 & 2 \\
\hline & S2_T1_P3 & 150 & 230 & 250 & 157 & 525.9 & 23.02 & 270 & 0.045 & 3 \\
\hline & $\mathrm{S} 2 \_\mathrm{T} 2 \_\mathrm{P} 2$ & 150 & 230 & 250 & 157 & 525.9 & 22.39 & 270 & 0.045 & 2 \\
\hline & S2_T2_P3 & 150 & 230 & 250 & 157 & 525.9 & 22.39 & 270 & 0.045 & 3 \\
\hline \multirow{4}{*}{ Loreto et al. [7] } & L_1_X & 305 & 129 & 152 & 213.9 & 414 & 29.1 & 280 & 0.05 & 1 \\
\hline & L_4_X & 305 & 129 & 152 & 213.9 & 414 & 29.1 & 280 & 0.05 & 4 \\
\hline & H_1_X & 305 & 129 & 152 & 213.9 & 414 & 42.91 & 280 & 0.05 & 1 \\
\hline & H_4_X & 305 & 129 & 152 & 213.9 & 414 & 42.91 & 280 & 0.05 & 4 \\
\hline
\end{tabular}

where

$$
\begin{aligned}
& \beta_{p}=\sqrt{\frac{2-b_{p} / b_{c}}{1+b_{p} / b_{c}},} \\
& \beta_{L}= \begin{cases}1, & \text { if } L \geq L_{e}, \\
\sin \frac{\pi L}{2 L_{e}}, & \text { if } L<L_{e},\end{cases} \\
& L_{e}=\sqrt{\frac{E_{p} t_{p}}{\sqrt{f_{c}^{\prime}}},}
\end{aligned}
$$

where $b_{p}$ is the width of the bonded plate, $b_{c}$ is the width of the concrete block, $L$ is the bond length, $L_{e}$ is the effective bond length, $E_{p}$ is the elastic modulus of plate, $t_{p}$ is the thickness of the bonded plate, $f_{c}^{\prime}$ is the cylinder compressive strength for concrete, and $\alpha$ is the reduction factor and given as 0.427 by Teng et al. [15].

In the FRCM composite, the total nominal thickness of FRP fabric $t_{p}$ is defined by

$$
t_{p}=t_{1} \times n,
$$

where $t_{1}$ is the nominal thickness of 1-ply FRP fabric and $n$ is the number of layers.

Meanwhile, D'Ambrisi et al. [11] suggested through the experimental study for bond-slip behavior between an FRCM composite and concrete that the FRP fabric strain corresponding to its debonding $\varepsilon_{f \text {,deb }}$ decreases at the rate of $1 / \sqrt{n}$ with the higher amount of FRP fabric. Therefore, (3) can be modified into (4) in the bond strength model for FRCM composite, considering the slippage between FRP fabric and matrix:

$$
t_{p}=t_{1} \times \sqrt{n}
$$

Finally, the bond strength model for the FRCM composite is proposed as

$$
\sigma_{\mathrm{FRCM}}=\alpha \beta_{p} \beta_{L} \sqrt{\frac{E_{p} \sqrt{f_{c}^{\prime}}}{t_{1} \sqrt{n}}},
$$

where $\sigma_{\text {FRCM }}$ is the stress in the FRCM composite at debonding.

In addition, the coefficient $\alpha$ should be calibrated to account for the difference between FRCM and EBR. The test data of RC beams strengthened with FRCM composite were collected to calibrate the $\alpha$ value. Table 7 shows the collected test database for $\mathrm{RC}$ beams strengthened with FRCM composite. The database consists of the geometries and material properties of $18 \mathrm{RC}$ beams tested under fourpoint or three-point loading.

For the database given in Table 7, as the strain in the FRP fabric at the critical section was not reported, the experimental value of stress in the FRP fabric at debonding, $f_{f, \text { deb }}$, was deduced from the experimental debonding moment, $M_{u \text {,deb }}$, using the conventional reinforced concrete theory. Figure 8 shows the analytical model to deduce the experimental stress in the FRP fabric at debonding from the experimental debonding moment. It illustrates the assumed basic analytical conditions of internal strain, stress, and resultant force for a FRCM-strengthened section at ultimate stage. Both strain compatibility and internal force equilibrium in the analytical model were assumed to relate the stress in the FRP fabric to the applied moment. 


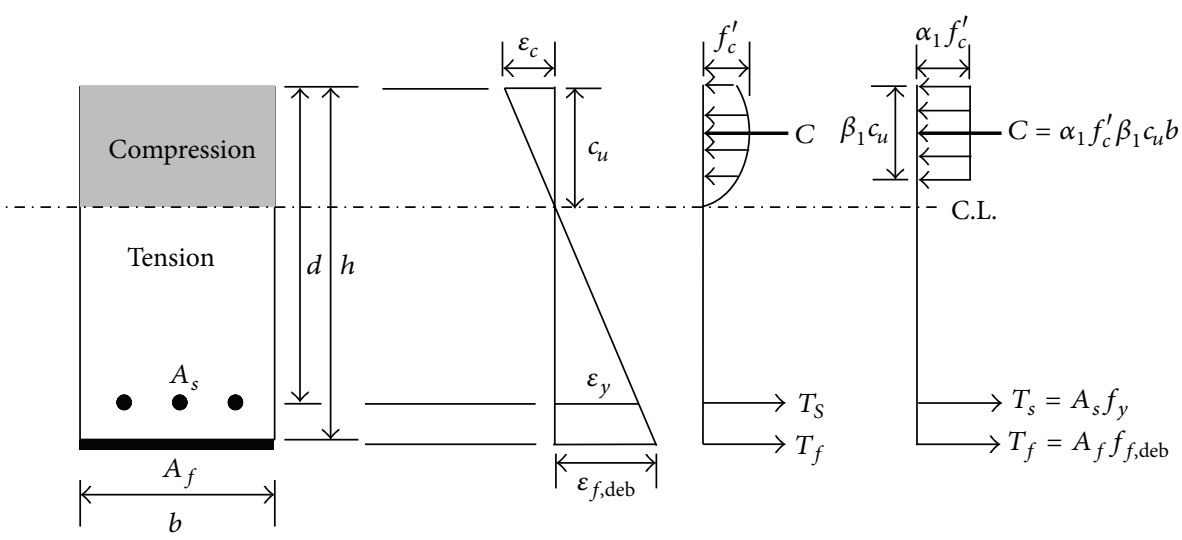

FIgURE 8: Analytical model at the ultimate stage.

In Figure 8, the experimental debonding moment, $M_{u, \mathrm{deb}}$, is expressed according to (6a), (6b), (6c), (6d), (6e), (6f), (6g), and $(6 \mathrm{~h})$. The tensile steel was assumed to be yielded based on the test results in the section analysis:

$$
M_{u, \mathrm{deb}}=M_{s}+M_{f}
$$

where

$$
\begin{aligned}
M_{s} & =A_{s} f_{y}\left(d-\frac{\beta_{1} c_{u}}{2}\right), \\
M_{f} & =n A_{f} f_{f, \text { deb }}\left(h-\frac{\beta_{1} c_{u}}{2}\right), \\
\beta_{1}\left(c_{u}\right) & =\frac{4 \varepsilon_{c}^{\prime}-\varepsilon_{c}\left(c_{u}\right)}{6 \varepsilon_{c}^{\prime}-2 \varepsilon_{c}\left(c_{u}\right)}, \\
\varepsilon_{c}^{\prime} & =\frac{1.7 f_{c}^{\prime}}{E_{c}}, \\
E_{c} & =4,700 \sqrt{f_{c}^{\prime},} \\
f_{f, \mathrm{deb}} & =E_{f} \varepsilon_{f, \mathrm{deb}}, \\
\varepsilon_{c} & =\frac{c_{u}}{h-c_{u}} \varepsilon_{f, \mathrm{deb}},
\end{aligned}
$$

where $M_{s}$ is the contribution of steel reinforcement to nominal flexural strength, $M_{f}$ is the contribution of FRP reinforcement to nominal flexural strength, $A_{s}$ is the area of steel reinforcement, $M_{f}$ is the area of FRP reinforcement, $d$ is the distance from extreme compression fiber to centroid of tension reinforcement, $h$ is the long side cross-sectional dimension of rectangular, $f_{y}$ is the yield stress of steel reinforcement, $\varepsilon_{c}^{\prime}$ is the compressive strain corresponding to $f_{c}^{\prime}, E_{c}$ is the modulus of elasticity of concrete, $E_{f}$ is the modulus of elasticity of FRP fabric, $\varepsilon_{f \text {,deb }}$ is the strain in the FRCM composite at debonding, $c_{u}$ is the neutral axis depth at the ultimate moment, $\beta_{1}$ is the concrete stress block factor, and $\varepsilon_{c}$ is the concrete compressive strain. $(6 c)$

The stress $f_{f \text {,deb }}$ can be expressed as (7) by using (6a)-

$$
f_{f, \mathrm{deb}}=\frac{M_{u, \mathrm{deb}}-A_{s} f_{y}\left(d-\beta_{1} c_{u} / 2\right)}{n A_{f}\left(h-\beta_{1} c_{u} / 2\right)} .
$$

Also, the stress $f_{f \text {,deb }}$ should satisfy the internal force equilibrium expressed as (8a), (8b), (8c), (8d), and (8e):

$$
T_{s}+T_{f}=C
$$

where

$$
\begin{aligned}
T_{s} & =A_{s} f_{y}, \\
T_{f} & =n A_{f} f_{f, \mathrm{deb}}, \\
C & =\alpha_{1} f_{c}^{\prime} \beta_{1} c_{u} b, \\
\alpha_{1}\left(c_{u}\right) & =\frac{3 \varepsilon_{c}^{\prime} \varepsilon_{c}\left(c_{u}\right)-\left[\varepsilon_{c}\left(c_{u}\right)\right]^{2}}{3 \beta_{1}\left(c_{u}\right) \varepsilon_{c}^{\prime 2}},
\end{aligned}
$$

where $T_{s}$ is the tensile force for steel reinforcement, $T_{f}$ is the tensile force for FRCM composite, $C$ is the compressive force for concrete, and $\alpha_{1}$ is the concrete stress block factor.

The stress $f_{f \text {,deb }}$ was computed with the trial and error method using (7) and (8a)-(8e). The value of $\alpha$ for each beam given in Table 7 was calculated with (9) derived from $f_{f \text {, deb }}$ and (5):

$$
\alpha=\frac{f_{f, \mathrm{deb}}}{\beta_{p} \beta_{L} \sqrt{E_{p} \sqrt{f_{c}^{\prime}} / t_{1} \sqrt{n}}} .
$$

Finally, Figure 9 shows the $\alpha$ values calculated for test beams presented in Table 7 . The average $\alpha$ value for total beams was taken as 0.729 from a regression analysis.

In order to verify the proposed bond strength model for FRCM, it was used to numerically predict the flexural capacity of the FRCM-strengthened RC beams. Table 8 shows the comparison between test results and analytical results. The ratio of test results to predicted values ranged from 
TABLE 8: Comparisons between test results and analytical results.

\begin{tabular}{|c|c|c|c|c|}
\hline Reference & Specimen ID & $P_{u . \text { test }}(\mathrm{kN})$ & $P_{u \text {.analysis }}(\mathrm{kN})$ & $P_{u . \text { test }} / P_{u \text {.analysis }}$ \\
\hline \multirow{6}{*}{ Project study } & A1 & 58.58 & 58.57 & 1.00 \\
\hline & $\mathrm{A} 2$ & 62.70 & 71.26 & 0.88 \\
\hline & A3 & 83.60 & 82.25 & 1.02 \\
\hline & $\mathrm{B} 1$ & 65.52 & 62.70 & 1.05 \\
\hline & B2 & 73.68 & 78.14 & 0.94 \\
\hline & B3 & 97.76 & 91.46 & 1.07 \\
\hline \multirow{4}{*}{ Babaeidarabad et al. [1] } & L_1 & 67.70 & 62.51 & 1.08 \\
\hline & L_4 & 99.00 & 90.76 & 1.09 \\
\hline & H_1 & 63.00 & 64.76 & 0.97 \\
\hline & H_4 & 96.80 & 96.51 & 1.00 \\
\hline \multirow{4}{*}{ Ombres [6] } & S2_T1_P2 & 66.00 & 55.10 & 1.20 \\
\hline & S2_T1_P3 & 71.39 & 60.37 & 1.18 \\
\hline & $\mathrm{S} 2 \_\mathrm{T} 2 \_\mathrm{P} 2$ & 52.86 & 54.89 & 0.96 \\
\hline & $\mathrm{S} 2 \_\mathrm{T} 2 \_\mathrm{P} 3$ & 55.71 & 60.10 & 0.93 \\
\hline \multirow{4}{*}{ Loreto et al. [7] } & L_1_X & 45.01 & 44.25 & 1.02 \\
\hline & L_4_X & 65.30 & 71.50 & 0.91 \\
\hline & H_1_X & 42.00 & 46.48 & 0.90 \\
\hline & H_4_X & 65.76 & 77.48 & 0.85 \\
\hline \multicolumn{2}{|c|}{ Mean } & & & 1.00 \\
\hline \multicolumn{2}{|c|}{ Standard deviation } & & & 0.094 \\
\hline
\end{tabular}

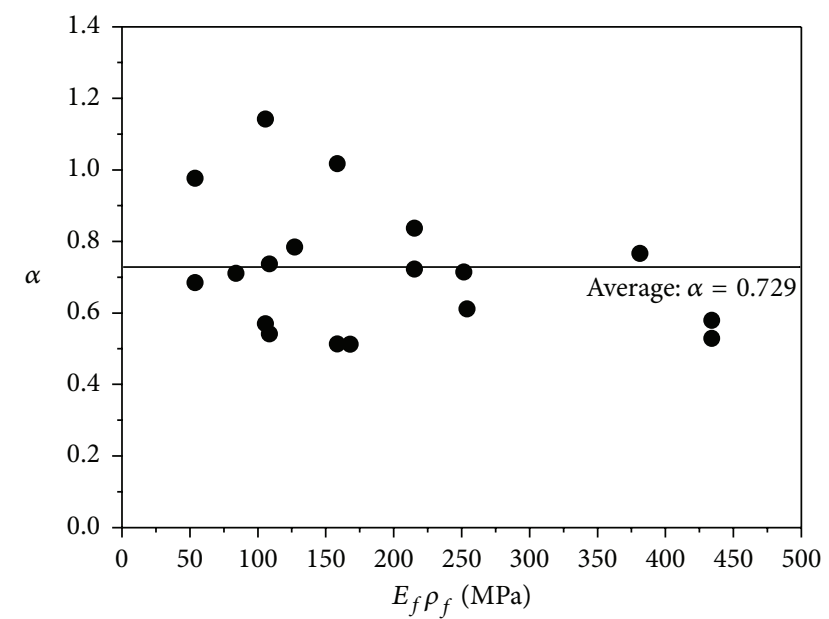

Figure 9: Computed $\alpha$ values.

0.85 to 1.20 . The average and standard deviation of the ratios were 1.00 and 0.094 , respectively. It should be noted from comparison that the proposed bond strength model for FRCM can be used to predict the flexural capacity of the FRCM-strengthened beam because test results agree well with the predicted values.

4.2. Load-Deflection Curve. The comparisons of loaddeflection curves for representative beams of Table 7 are presented in Figure 10. Theoretical curves consisted of a trilinear diagram. Thus, the corresponding load and midspan deflection at three stages, namely, cracking, yielding, and ultimate stage, were calculated using the moment capacity and strain compatibility. The midspan deflection, $\Delta$, of flexural beam with simple supports under three- and fourpoint load was calculated from the following equations, respectively:

$$
\begin{aligned}
& \Delta_{3, p}=\frac{1}{12} \frac{M L^{2}}{E_{c} I}, \\
& \Delta_{4, p}=\frac{69}{648} \frac{M L^{2}}{E_{c} I},
\end{aligned}
$$

where $M$ is the applied moment, $L$ is the beam net span, and $I$ is the corresponding moment of inertia. The term $M / E_{c} I$ is the curvature of the cross section at midspan, $\chi$, calculated from

$$
\chi=\frac{\varepsilon_{s}}{d-c},
$$

where $c$ is the corresponding neutral axis depth and $\varepsilon_{s}$ is the corresponding stress of tensile rebar.

The corresponding load at ultimate stage was derived from the moment computed using the proposed bond strength model. As shown in Figure 10, the predicted loaddeflection response of FRCM-strengthened beams is in satisfactory agreement with experimental results. In particular, the slope between yielding and ultimate stage, namely, the debonding in the predicted diagram, agrees with test results well. It results from the accuracy of the proposed bond strength model, predicting the FRP fabric stress at debonding. 


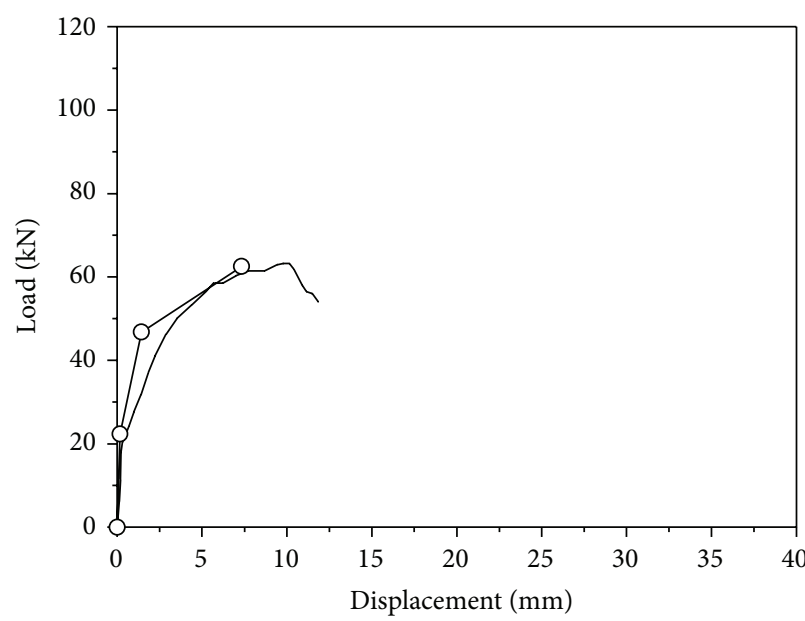

$\rightarrow$ L_1_exp

-O- Analytical

(a) L_1

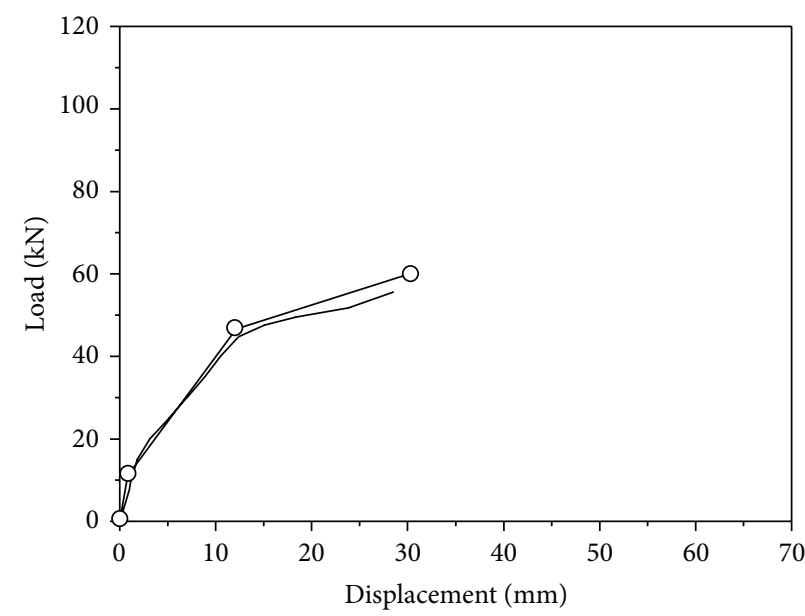

$\rightarrow$ S2_T2_P3_exp

-O- Analytical

(c) S2_T2_P3

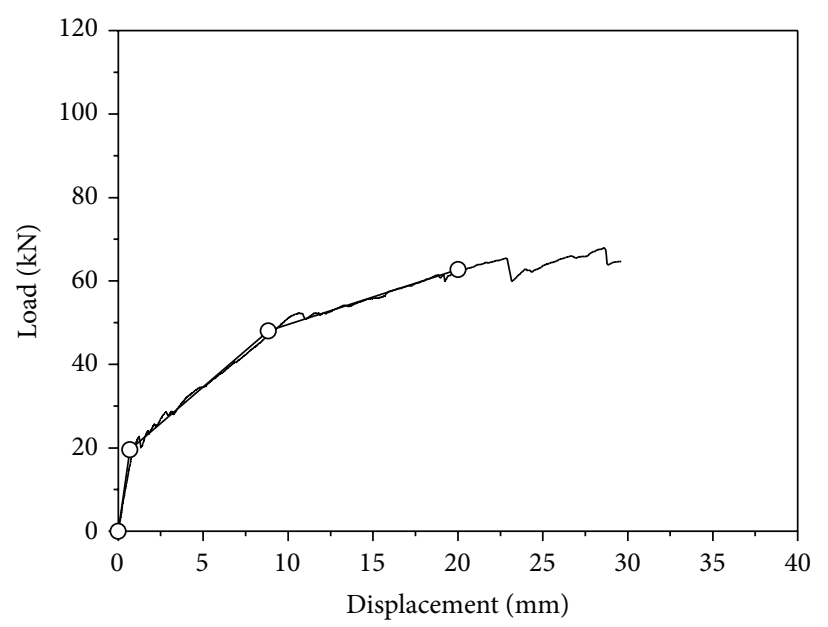

$\rightarrow$ B1_exp

-O- Analytical

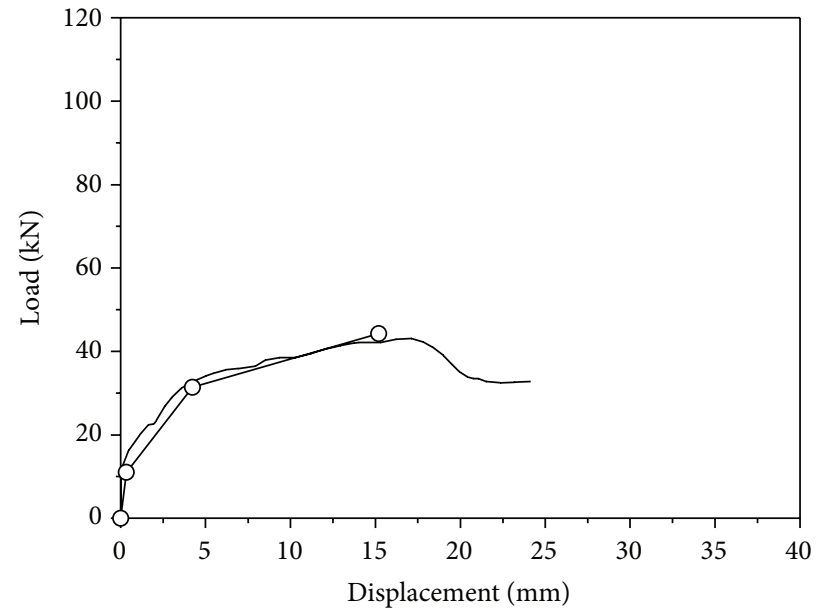

$\rightarrow$ L_1_X_exp

$-0-$ Analytical

(b) L_1_X

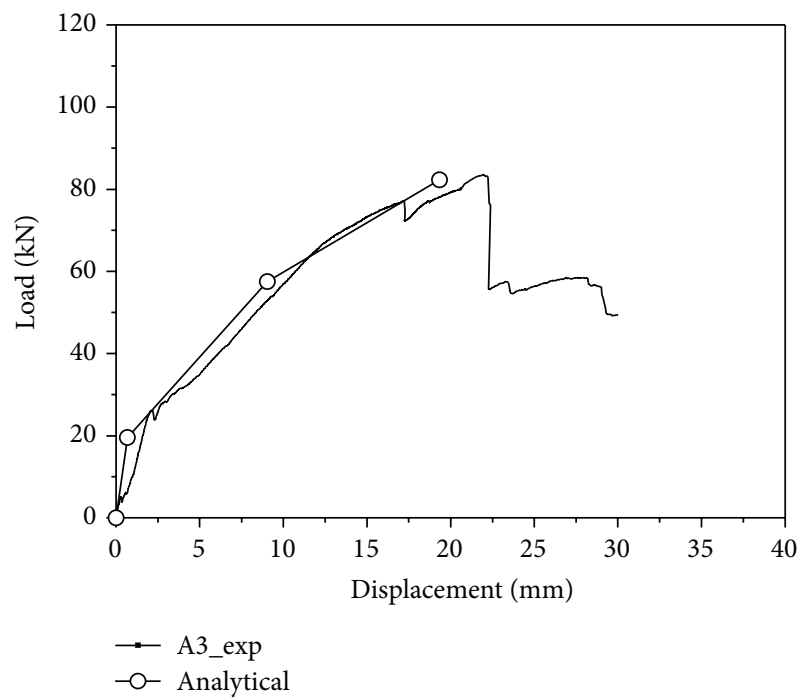

(d) $\mathrm{A} 3$

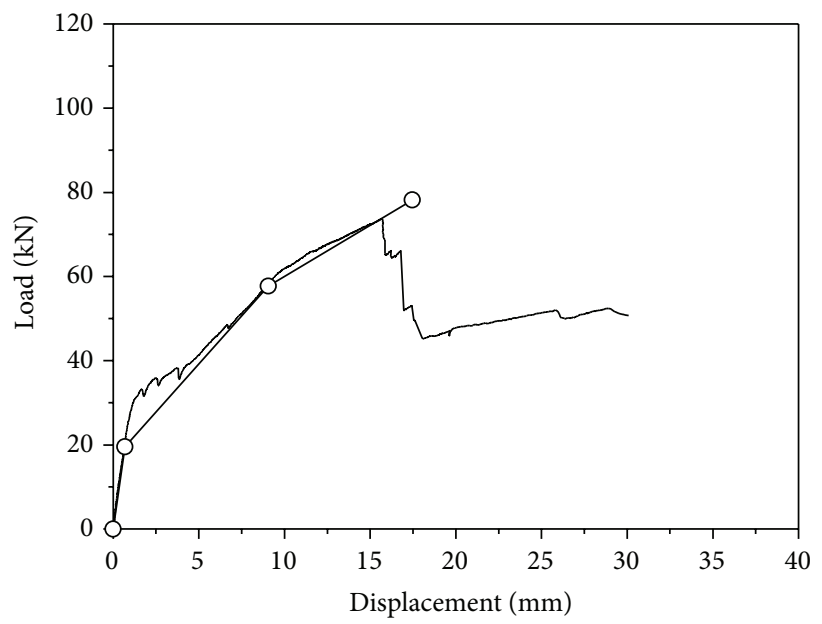

$\rightarrow$ B2_exp

-O- Analytical

(e) B1

(f) $\mathrm{B} 2$

FIgURE 10: Comparisons of load-displacement curves. 


\section{Conclusion}

The following conclusions are drawn from the results.

(1) The flexural strengths of beams strengthened with FRCM composite ranged from $131.7 \%$ to $219.8 \%$ relative to a Control specimen, increasing with a higher amount of FRP fabric. Also, all of them failed by the debonding of the FRCM composite.

(2) Before initial crack occurrence, the relationship of load-FRCM fabric strain was linear. However, the slippage between FRP fabric and cementitious matrix increased with the higher load after crack formation. Consequently, it should be noted that the strain distribution of a section at low strain can be assumed to be linear, but it cannot be regarded as linear at the high strain level, due to the slippage between FRP fabric and cementitious matrix.

(3) Although the maximum strains of specimens in Group B were higher than those of specimens in Group A, these were less than $70 \%$ of the strain corresponding to FRP fabric rupture, $17,500 \mu \varepsilon$. These premature failures were due to the debonding of the FRCM composite.

(4) A new bond strength model, which was based on the model by Teng et al. [15] and which considered the slippage between the FRP fabric and matrix, was proposed to predict the strengthening performance of the FRCM composite. The ratios of collected test results to predicted values ranged from 0.85 to 1.20 . The average and standard deviation of the ratios were 1.00 and 0.094 , respectively. Thus, it could be concluded that the proposed bond strength model for FRCM can be used to predict the flexural capacity of the FRCM-strengthened beam.

(5) The predicted load-deflection response of FRCMstrengthened beams at cracking, yielding, and ultimate stage was in satisfactory agreement with experimental results, confirming the accuracy of the proposed bond strength model.

\section{Conflict of Interests}

The authors declare no conflict of interests.

\section{Acknowledgment}

This research was supported by Basic Science Research Program through the National Research Foundation of Korea (NRF) funded by the Ministry of Science, ICT \& Future Planning (NRF-2013R1A1A2012521).

\section{References}

[1] S. Babaeidarabad, G. Loreto, and A. Nanni, "Flexural strengthening of RC beams with an externally bonded fabric-reinforced cementitious matrix," Journal of Composites for Construction, vol. 18, no. 5, 2014.
[2] Y. A. Al-Salloum, H. M. Elsanadedy, S. H. Alsayed, and R. A. Iqbal, "Experimental and numerical study for the shear strengthening of reinforced concrete beams using textilereinforced mortar," Journal of Composites for Construction, vol. 16, no. 1, pp. 74-90, 2012.

[3] A. D'Ambrisi and F. Focacci, "Flexural strengthening of RC beams with cement-based composites," Journal of Composites for Construction, vol. 15, no. 5, pp. 707-720, 2011.

[4] L. Ombres, "Analysis of the bond between fabric reinforced cementitious mortar (FRCM) strengthening systems and concrete," Composites Part B: Engineering, vol. 69, pp. 418-426, 2015.

[5] C. G. Papanicolaou, T. C. Triantafillou, M. Papathanasiou, and K. Karlos, "Textile reinforced mortar (TRM) versus FRP as strengthening material of URM walls: out-of-plane cyclic loading," Materials and Structures, vol. 41, no. 1, pp. 143-157, 2008.

[6] L. Ombres, "Flexural analysis of reinforced concrete beams strengthened with a cement based high strength composite material," Composite Structures, vol. 94, no. 1, pp. 143-155, 2011.

[7] G. Loreto, L. Leardini, D. Arboleda, and A. Nanni, "Performance of RC slab-type elements strengthened with fabricreinforced cementitious-matrix composites," Journal of Composites for Construction, vol. 18, no. 3, 2014.

[8] American Concrete Institute, "Design and construction guide of externally bonded FRCM system for concrete and masonry repair and strengthening," ACI 549, American Concrete Institute, Farmington Hills, Mich, USA, 2013.

[9] American Concrete Institute (ACI), "Building code requirements for reinforced concrete," ACI 318, American Concrete Institute, Farmington Hills, Mich, USA, 2011.

[10] A. D’Ambrisi, L. Feo, and F. Focacci, "Experimental and analytical investigation on bond between carbon-FRCM materials and masonry," Composites Part B: Engineering, vol. 46, pp. 1520, 2013.

[11] A. D’Ambrisi, L. Feo, and F. Focacci, "Experimental analysis on bond between PBO-FRCM strengthening materials and concrete," Composites B: Engineering, vol. 44, no. 1, pp. 524-532, 2013.

[12] ASTM International, "Standard test method for compressive strength of cylindrical concrete specimens," ASTM C39/C39M, ASTM International, West Conshohocken, Pa, USA, 2013.

[13] ASTM, "Standard test methods and definitions for mechanical testing of steel products," ASTM A370, ASTM International, West Conshohocken, Pa, USA, 2013.

[14] ASTM International, "Standard test method for compressive strength of hydraulic cement mortars," ASTM C109/C109M, ASTM International, West Conshohocken, Pa, USA, 2013.

[15] J. G. Teng, S. T. Smith, J. Yao, and J. F. Chen, "Intermediate crack-induced debonding in RC beams and slabs," Journal of Construction and Building Materials, vol. 17, no. 6-7, pp. 447462, 2003. 

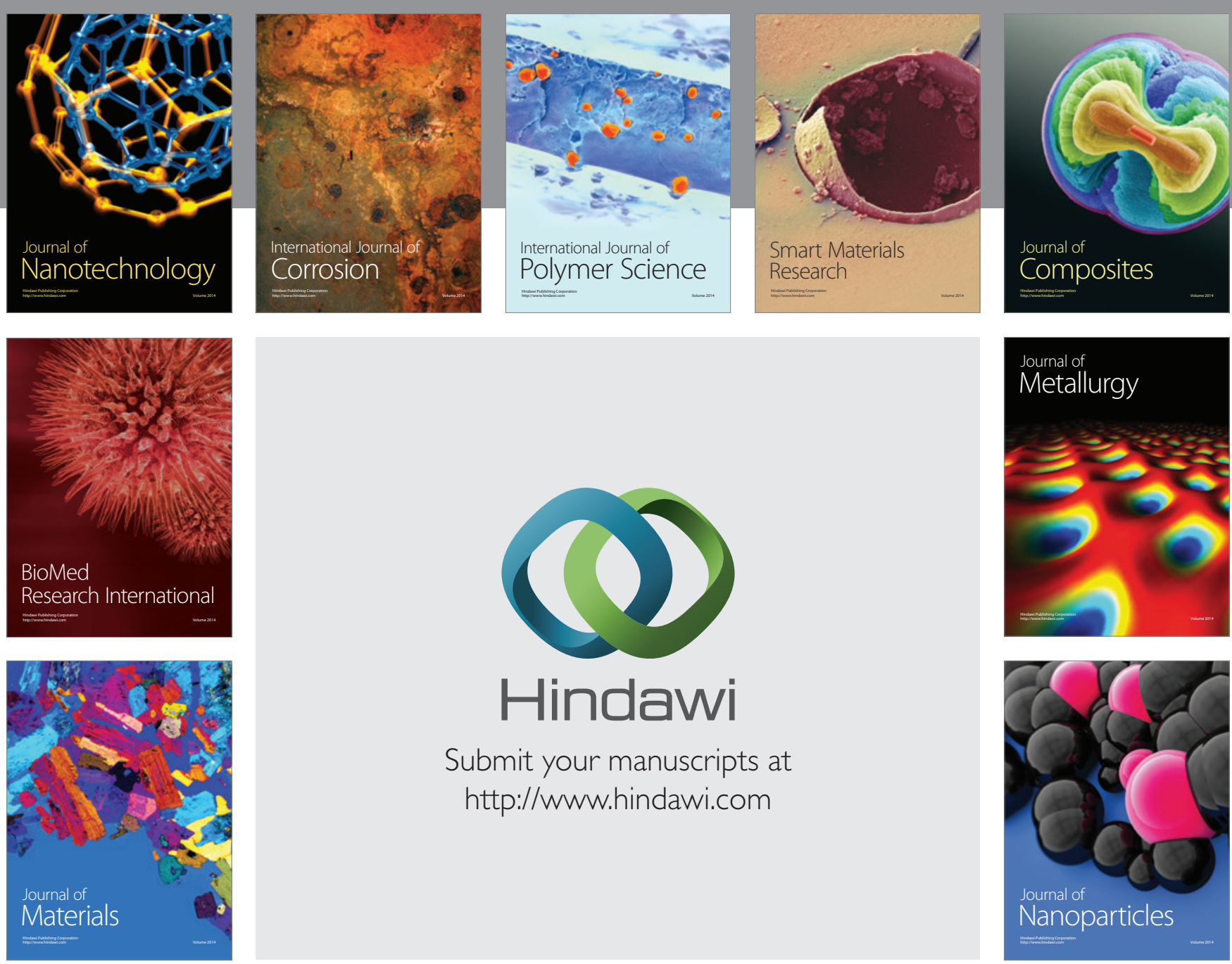

Submit your manuscripts at http://www.hindawi.com
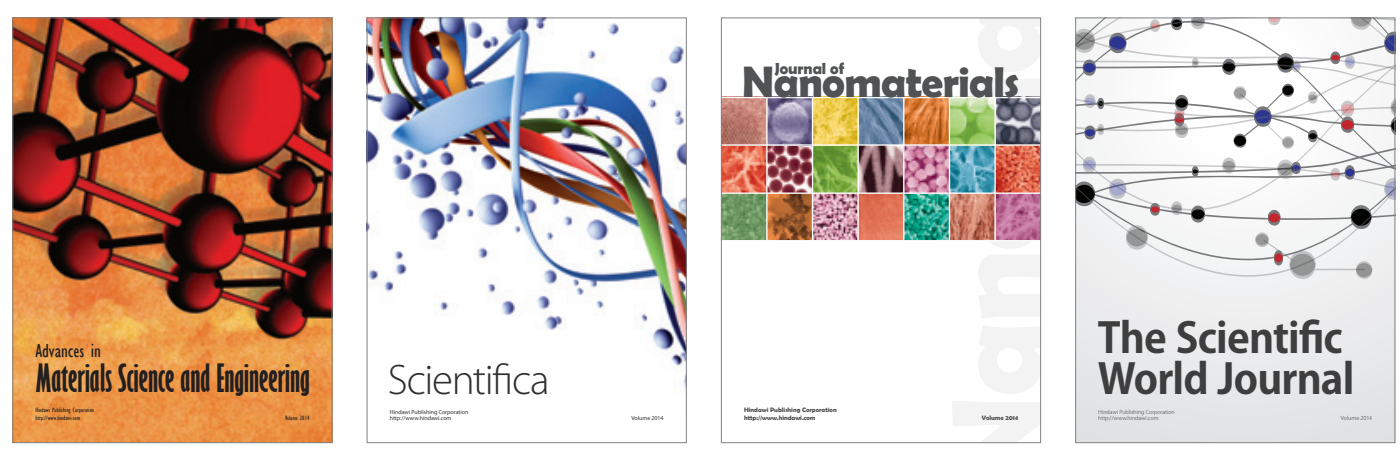

\section{The Scientific World Journal}
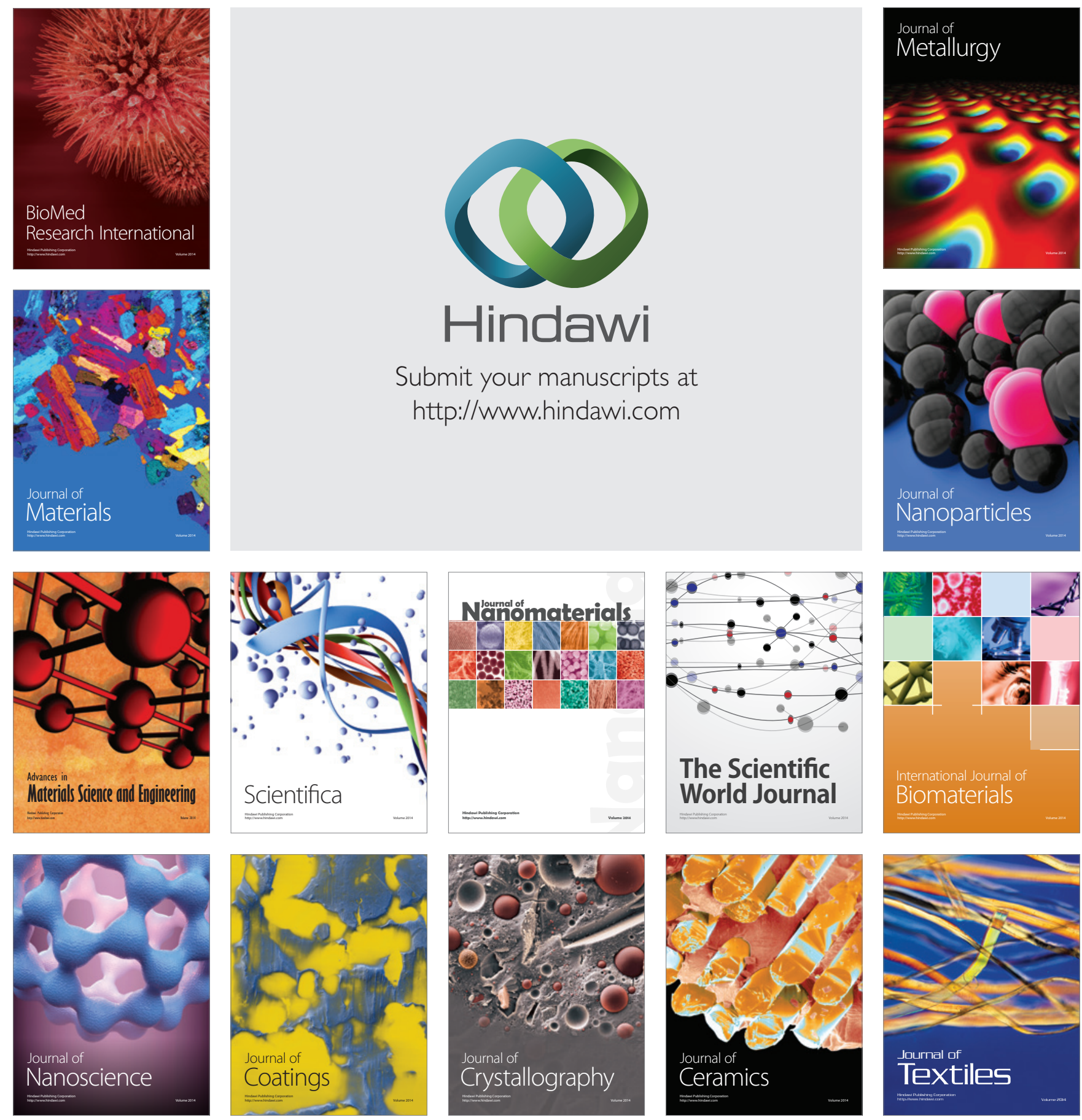